\title{
Socio-economic differences in eating-related attitudes, behaviours and environments of adolescents
}

\author{
Jennifer Utter ${ }^{1, *}$, Simon Denny ${ }^{2}$, Sue Crengle ${ }^{3}$, Shanthi Ameratunga ${ }^{1}$, Terryann Clark ${ }^{4}$, \\ Ralph Maddison ${ }^{5}$ and Teuila Percival ${ }^{6}$ \\ 'Epidemiology and Biostatistics, School of Population Health, University of Auckland, Private Bag 92019, \\ Auckland, New Zealand: ${ }^{2}$ Community Paediatrics, School of Population Health, University of Auckland, \\ Auckland, New Zealand: ${ }^{3}$ Te Kupenga Haoura Māori, School of Population Health, University of Auckland, \\ Auckland, New Zealand: ${ }^{4}$ School of Nursing, University of Auckland, Auckland, New Zealand: ${ }^{5}$ Clinical Trials \\ Research Unit, School of Population Health, University of Auckland, Auckland, New Zealand: 'Pacific Health, \\ School of Population Health, University of Auckland, Auckland, New Zealand
}

\section{Submitted 23 November 2009: Accepted 10 May 2010: First published online 25 June 2010}

\begin{abstract}
Objective: The aim of the present study was to investigate the relationship between area-level socio-economic status and healthy and less healthy eating behaviours among adolescents and to determine whether the relationship between area-level socio-economic status and dietary behaviours was related to the relevant attitudes and environments.

Design: Data were collected as part of Youth'07, a nationally representative survey of the health and well-being of New Zealand youth.

Setting: New Zealand secondary schools, 2007.

Subjects: A total of 9107 secondary-school students in New Zealand.

Results: Students from more deprived areas perceived more supportive school environments and cared as much about healthy eating as students in more affluent areas. However, these students were significantly more likely to report consuming fast food, soft drinks and chocolates.

Conclusions: Addressing area-level socio-economic disparities in healthy eating requires addressing the availability, affordability and marketing of unhealthy snack foods, particularly in economically deprived areas.
\end{abstract}

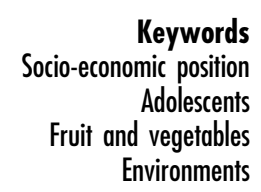

Healthy eating plays a critical role in the prevention of chronic diseases ${ }^{(1)}$ and eating habits established during adolescence may have long-lasting effects. Most notably, the establishment of overweight/obesity during childhood and adolescence is predictive of overweight/obesity into adulthood $^{(2-4)}$. Inverse socio-economic gradients in the prevalence of obesity ${ }^{(5,6)}$ and chronic diseases, such as $\mathrm{CVD}^{(7)}$ and some cancers ${ }^{(8)}$, are documented in many Western countries. Similarly, previous research suggests that less healthy eating behaviours are also related to socioeconomic status. For example, adolescents experiencing greater socio-economic deprivation are less likely to eat adequate fruit and vegetables ${ }^{(9-11)}$ and more likely to consume snack foods and fast food ${ }^{(9,12)}$, skip breakfast ${ }^{(13,14)}$, watch television $^{(15,16)}$ and buy food outside the home ${ }^{(17)}$.

A range of interrelated factors are thought to influence adolescent eating behaviours. These include psychosocial factors (e.g. taste preferences and knowledge), biological factors (e.g. hunger and growth), the social environment (e.g. socio-economic factors, support and media) and the physical environment (e.g. access to fast food and supermarkets ${ }^{(18)}$. Previous research has found that taste preferences and home availability of fruit and vegetables are among the most important factors associated with adolescent fruit and vegetable consumption ${ }^{(10)}$. Furthermore, access to supermarkets positively influences fruit and vegetable intake ${ }^{(19)}$. Research has also suggested that school policies can significantly impact on student eating behaviours ${ }^{(20)}$. Less is known about how area-level socio-economic gradients in eating behaviours are related to the psychosocial and environmental factors influencing those behaviours. One regional study in Australia found that some of the social cognitive constructs associated with adolescent eating behaviours (e.g. self-efficacy for increasing fruit, social support for healthy eating and food availability in the home) were positively associated with socio-economic position ${ }^{(9)}$. The aim of the present study was to investigate the relationship between socio-economic status and healthy and less healthy eating behaviours among adolescents and to determine whether the arealevel socio-economic relationships in dietary behaviours were related to relevant attitudes and environments. 


\section{Methods}

\section{Study design}

Data were collected as part of Youth'07, a survey of the health and well-being of New Zealand youth ${ }^{(21)}$. The Youth'07 survey was a nationally representative survey of high-school students conducted in 2007. The survey aimed to document the prevalence of key health and well-being issues, including nutrition and activity behaviours.

The Youth'07 survey utilized a two-stage sampling design. First, 115 schools were randomly selected for participation from the 389 eligible secondary schools in New Zealand and ninety-six agreed to participate (school response rate 84\%). From the participating schools, students were randomly selected from the school rolls for participation. Of the 12355 students selected, 9107 students agreed (student response rate $74 \%$ ). The most common reasons for students not participating were being absent from school, being unavailable or declining to take part ${ }^{(21)}$.

School principals consented to participate on behalf of the Boards of Trustees. Students and their parents were provided with information sheets about the survey. The students themselves consented to participate in the survey. The University of Auckland Human Subject Ethics Committee granted ethical approval for the study. The survey questions and data collection methods were piloted for comprehension and acceptability ${ }^{(22)}$ and refinements were made before data collection.

All data collection took place at school during the school day. Upon arrival at the survey room, students were given an anonymous login code to access the survey. The survey included a 622-item multimedia questionnaire administered on a Nokia Internet tablet and identification of their census meshblock number (based on their residential address) to determine the extent of their neighbourhood deprivation. The multimedia nature of the questionnaire meant that all students could read each of the question and response options themselves, while listening to the questions and responses being read aloud through headphones.

\section{Measures}

Age, gender and ethnicity were determined by self-report. Ethnicity was assessed using New Zealand census questions ${ }^{(23)}$ in which participants select all ethnic groups that they identify with. Approximately $40 \%$ of students identified with more than one ethnic group ${ }^{(21)}$. To facilitate statistical analyses, ethnic populations were prioritized in the following order: Māori, Pacific, Asian, Other ethnicity and European.

Students were assigned to a level of small area deprivation by linking their residential meshblock number to the 2006 New Zealand Deprivation Index ${ }^{(24)}$. This index assesses eight dimensions of deprivation using 2006 census data, based on small-area geographical units. The index deciles were categorized into three groups reflecting low deprivation (1-3), middle levels of deprivation (4-7) and high deprivation (8-10).

\section{Eating behaviours}

Breakfast ( $n$ 8789) and lunch consumption ( $n$ 7888) were assessed with the questions, 'How often do you eat breakfast/lunch?' Responses were categorized into 'always' or 'sometimes/hardly ever'. Family meal consumption was assessed with the question, 'During the past $7 \mathrm{~d}$, how many times did all, or most, of your family living in your house eat a meal together?' Responses were dichotomized as 'five or more times a week' and 'never or one to four times a week'. Fruit and vegetable consumption ( $n$ 8710) was assessed with three separate questions, 'During the past $7 \mathrm{~d}$, how often did you eat any of the following (fruit/potatoes, kumara, taro, etc./ vegetables (not including potatoes, kumara and taro))?' Students were categorized as meeting the recommendation for 'five or more fruit and vegetables a day' ${ }^{\text {(25) }}$ if they responded that they consumed fruit twice a day or more often and the sum of vegetables and potatoes, kumara or taro three times a day or more often. Fast food/takeaway consumption ( $n$ 8745) was assessed with two questions, 'During the past $7 \mathrm{~d}$, how often did you eat food from a fast-food place (e.g. McDonalds, KFC, Burger King, Subway, Pizza Hut)/other takeaways or fast-food shops (fish and chips, Chinese takeaways)?' Students were categorized as consuming fast food/takeaways 'four or more times a week' if they responded as such to either of the questions. Consumption of chocolates ( $n$ 8719), potato chips ( $n$ 8708) and soft drinks ( $n$ 8697) was assessed with three items asking, 'During the past $7 \mathrm{~d}$, how often did you eat/drink any of the following (chocolate, sweets or lollies/potato chips, burger rings, twisties, etc./fizzy or soft drinks (e.g. Coke, Sprite and Fanta))?' Responses were dichotomized at 'once a day or more often' and 'less than once a day'. The less healthy behaviours (consumption of fast food, chocolates, potato chips and soft drinks) were dichotomized at the highfrequency categories as it is recognized that these types of foods should not be consumed so frequently.

\section{Eating attitudes and environments}

How much students care about eating healthy food ( $n$ 8672) was assessed with the question, 'How much do you care about eating healthy food?' Responses were dichotomized into 'very much' and 'some, a little, or not at all'. Home availability of fresh fruit and vegetables ( $n$ 8744)/ chocolates and sweets ( $n$ 8731)/soft drinks' ( $n$ 8706) were assessed by three items asking, 'How often are the following foods available to eat at home (fresh fruit or vegetables, chocolate or other sweets, fizzy drinks)?' Responses were dichotomized at 'usually or always' and 'sometimes or never'. Student perception of school support for healthy eating ( $n$ 8621) was assessed with the question, 'How much does your school encourage you to 
eat healthy food?' Responses were dichotomized as 'very much' and 'some, a little, or not at all'.

\section{Analysis}

All analyses were conducted using the survey procedures in the SAS statistical software package version 9.2 (SAS Institute, Cary, NC, USA). Prevalence estimates were derived using bivariate analyses to examine the associations between the variables of interest. Multiple logistic models were conducted to determine the relationship between area-level deprivation and eating behaviours, attitudes and environments, controlling for independent effects of age, gender and ethnicity.

\section{Results and discussion}

The associations between demographic characteristics and area-level socio-economic status of the study population are described in Table 1. Male and female participants were equally distributed across the levels of deprivation. There appeared to be fewer older adolescents (aged 15-17 years) in the high-deprivation areas. This may reflect that students attending schools in high-deprivation areas are more likely to leave school early compared with students in more affluent areas ${ }^{(26)}$. Pacific and Māori students were over-represented in the high-deprivation areas and this is consistent with previous reports of Pacific and Māori populations in New Zealand ${ }^{(27)}$.

Students living in high-deprivation areas were significantly less likely to always eat breakfast and lunch than students living in low-deprivation areas and these relationships were significant when controlling for age, gender and ethnicity (Table 2). However, there were no differences by area-level socio-economic deprivation in the proportion of students who eat five or more fruit and vegetables a day or eat meals with their families.
With regard to the less healthy eating behaviours, students in the high-deprivation areas were consistently more likely to consume fast food, chocolates, potato chips and soft drinks than students in less deprived areas. These findings are consistent with previous research that suggests that socio-economic position is associated with poorer nutrition profiles ${ }^{(28,29)}$.

Of interest, in the bivariate analysis, students living in the most deprived areas were more likely to meet the recommendation for fruit and vegetable consumption, but when the demographic variables (age, gender and ethnicity) were controlled for, the association was not significant. This finding is inconsistent with the majority of research suggesting that socio-economic position is positively associated with fruit and vegetable consumption ${ }^{(30)}$. One possible explanation for this inconsistency may be reflected in sociocultural factors influencing fruit and vegetable consumption. Previous research in New Zealand has reported higher fruit and vegetable consumption among Pacific children and Māori children, independent of socio-economic position ${ }^{(31)}$. The lack of association may also reflect recent initiatives targeting obesity prevention in more deprived areas in New Zealand. In 2004, the New Zealand government launched its national strategy for obesity prevention, subsequent to which many health promotion programmes were initiated in more deprived areas.

Students living in the most deprived areas were more likely to have chocolates $(P=0 \cdot 01)$ and soft drinks $(P<0 \cdot 001)$ available at home and less likely to have fresh fruit and vegetables $(P<0 \cdot 001)$ available at home compared with students living in more affluent areas. This finding is consistent with previous research ${ }^{(9)}$ and is important since home availability of foods is an important predictor of adolescent eating behaviour ${ }^{(10)}$. It is noteworthy, however, that more than $25 \%$ of all students reported that they usually have chocolates or soft drinks available at home.

Table 1 Demographic characteristics of study sample by area-level deprivation

\begin{tabular}{|c|c|c|c|c|c|c|}
\hline & \multicolumn{2}{|c|}{ Low-deprivation areas } & \multicolumn{2}{|c|}{ Middle-deprivation areas } & \multicolumn{2}{|c|}{ High-deprivation areas } \\
\hline & $n$ & $\%$ & $n$ & $\%$ & $n$ & $\%$ \\
\hline Total & 3218 & $36 \cdot 3$ & 3397 & $38 \cdot 3$ & 2250 & $25 \cdot 4$ \\
\hline \multicolumn{7}{|l|}{ Gender } \\
\hline Male & 1650 & $34 \cdot 6$ & 1919 & $40 \cdot 1$ & 1212 & $25 \cdot 2$ \\
\hline Female & 1565 & $38 \cdot 5$ & 1470 & $36 \cdot 1$ & 1028 & $25 \cdot 3$ \\
\hline \multicolumn{7}{|l|}{ Age (years) } \\
\hline$\leq 13$ & 578 & $32 \cdot 2$ & 690 & $38 \cdot 3$ & 532 & $29 \cdot 6$ \\
\hline 14 & 728 & $35 \cdot 8$ & 783 & $38 \cdot 4$ & 532 & $25 \cdot 8$ \\
\hline 15 & 736 & $38 \cdot 0$ & 733 & $37 \cdot 8$ & 469 & $24 \cdot 2$ \\
\hline 16 & 644 & $38 \cdot 0$ & 655 & $38 \cdot 5$ & 400 & $23 \cdot 5$ \\
\hline$\geq 17$ & 530 & $38 \cdot 4$ & 535 & $38 \cdot 8$ & 313 & $22 \cdot 8$ \\
\hline \multicolumn{7}{|l|}{ Ethnicity } \\
\hline Asian & 424 & $38 \cdot 6$ & 481 & $43 \cdot 8$ & 194 & $17 \cdot 6$ \\
\hline European & 2168 & $46 \cdot 4$ & 1926 & $41 \cdot 0$ & 594 & $12 \cdot 5$ \\
\hline Māori & 334 & $20 \cdot 3$ & 577 & 34.9 & 743 & 44.9 \\
\hline Other & 219 & $42 \cdot 4$ & 190 & $36 \cdot 9$ & 107 & $20 \cdot 7$ \\
\hline Pacific & 70 & $7 \cdot 8$ & 221 & $24 \cdot 8$ & 601 & $67 \cdot 4$ \\
\hline
\end{tabular}


Approximately one-third of students care about healthy eating very much and there were no differences in students' concerns for healthy eating by area-level deprivation. Moreover, approximately $25 \%$ of students living in the most deprived areas reported that their school encouraged healthy eating, compared with 18\% of students in less deprived areas $(P=0 \cdot 024)$. Interventions to address inequalities in nutrition behaviours are not likely to be successful by addressing motivation or school support in more deprived areas. Although it is arguable that the attitudes and perceived school support were generally low, more effective initiatives to address eating behaviours of adolescents may address the social and physical environmental factors influencing food choices.

The strengths of the present study include the large, nationally representative sample of adolescents who participated in the study and the objective and validated measure of socio-economic deprivation used. There are a few limitations to our study that must be considered in interpreting these results. First, while we used an objective measure of socio-economic deprivation, it was an area-based measure. This is important as not all socioeconomically disadvantaged people live in deprived areas and vice versa ${ }^{(32)}$. Unfortunately, the Youth'07 survey did not include a robust measure of individual socioeconomic position. Second, given the breadth of this survey, in-depth dietary assessment was not possible. This is particularly relevant for our measure of fruit and vegetable consumption, as we were unable to validate our measure against a more robust measure. However, while the estimates of fruit and vegetable consumption may be compromised, we would not hypothesize that the strength and direction of the relationship with deprivation would be biased. Lastly, there may be other factors that explain the relationship between deprivation and eating behaviours. For example, the association between fastfood consumption and socio-economic deprivation may reflect the concentration of fast-food restaurants ${ }^{(33)}$ or marketing promotions for less healthy foods ${ }^{(34)}$ in racially segregated areas. This may be particularly relevant in New Zealand as Māori and Pacific populations are overrepresented on indicators of deprivation ${ }^{(27)}$.

\section{Conclusions}

Students from more socio-economically deprived areas perceived more supportive school environments and cared as much about healthy eating as students in more affluent areas. However, these students were significantly more likely to report consuming fast food, soft drinks and chocolates. Addressing socio-economic disparities in healthy eating requires addressing the availability, affordability and marketing of unhealthy snack foods, particularly in economically deprived areas. 


\section{Acknowledgements}

The Youth'07 study was funded by the Health Research Council of New Zealand (Grant 05/216), the Department of Labour, the Families Commission, the Accident Compensation Corporation of New Zealand, Sport and Recreation New Zealand, the Alcohol Advisory Council of New Zealand and the Ministries of Youth Development, Justice and Health. Support for the electronic communication of the Youth'07 project was provided by Vodafone New Zealand. The investigators for Youth'07 are Simon Denny, Shanthi Ameratunga, Terryann Clark, Sue Crengle, Robyn Dixon, Terry Fleming, Sally Merry, Elizabeth Robinson, David Schaaf, Jennifer Utter and Peter Watson. The Youth'07 Project Team includes Simon Denny, Sue Grant, Tania Milne, Ruth Herd, Joe Helu and Taciano Milfont. All authors have declared that they have no competing interests. J.U. was responsible for conception and design of paper, drafting article and interpretation of data. S.D. and R.M. were responsible for conception and design of paper, critical revision and approval of final version. S.C. and T.C. were responsible for the interpretation of data related to Māori students, critical revision of paper and approval of final version. S.A. was responsible for the interpretation of data related to Asian students, critical revision of paper and approval of final version. T.P. was responsible for the interpretation of data related to Pacific students, critical revision of paper and approval of final version. The authors would like to acknowledge the statistical support provided by Elizabeth Robinson.

\section{References}

1. World Health Organization (2003) Diet, Nutrition and the Prevention of Chronic Diseases. WHO Technical Report Series no. 916. Geneva: WHO.

2. Deshmukh-Taskar P, Nicklas TA, Morales M et al. (2006) Tracking of overweight status from childhood to young adulthood: the Bogalusa Heart Study. Eur J Clin Nutr 60, 48-57.

3. Freedman DS, Khan LK, Serdula MK et al. (2005) Racial differences in the tracking of childhood BMI to adulthood. Obes Res 13, 928-935.

4. Magarey AM, Daniels LA, Boulton TJ et al. (2003) Predicting obesity in early adulthood from childhood and parental obesity. Int J Obes Relat Metab Disord 27, 505-513.

5. Ministry of Health (2006) Embodying Social Rank: How Body Fat Varies with Social Status, Gender and Ethnicity in New Zealand. Public Health Intelligence Occasional Bulletin no. 34. Wellington: Ministry of Health.

6. Zhang Q \& Wang Y (2004) Trends in the association between obesity and socioeconomic status in US adults: 1971 to 2000. Obes Res 12, 1622-1632.

7. Cooper RS (2001) Social inequality, ethnicity and cardiovascular disease. Int J Epidemiol 30, Suppl. 1, S48-S52.

8. Kogevinas M, Pearce N, Susser M et al. (editors) (1997) Social Inequalities and Cancer. Lyon: International Agency for Research on Cancer.

9. Ball K, MacFarlane A, Crawford D et al. (2009) Can social cognitive theory constructs explain socio-economic variations in adolescent eating behaviours? A mediation analysis. Health Educ Res 24, 496-506.

10. Neumark-Sztainer D, Wall M, Perry C et al. (2003) Correlates of fruit and vegetable intake among adolescents. Findings from Project EAT. Prev Med 37, 198-208.

11. Wardle J, Jarvis MJ, Steggles N et al. (2003) Socioeconomic disparities in cancer-risk behaviors in adolescence: baseline results from the Health and Behaviour in Teenagers Study (HABITS). Prev Med 36, 721-730.

12. French SA, Story M, Neumark-Sztainer D et al. (2001) Fast food restaurant use among adolescents: associations with nutrient intake, food choices and behavioral and psychosocial variables. Int $J$ Obes Relat Metab Disord 25, 1823-1833.

13. Pearson N, Biddle SJ \& Gorely T (2009) Family correlates of breakfast consumption among children and adolescents. A systematic review. Appetite 52, 1-7.

14. Utter J, Scragg R, Mhurchu $\mathrm{CN}$ et al. (2007) At-home breakfast consumption among New Zealand children: associations with body mass index and related nutrition behaviors. J Am Diet Assoc 107, 570-576.

15. Gorely T, Marshall SJ \& Biddle SJ (2004) Couch kids: correlates of television viewing among youth. Int J Behav Med 11, 152-163.

16. Utter J, Scragg R \& Schaaf D (2006) Associations between television viewing and consumption of commonly advertised foods among New Zealand children and young adolescents. Public Health Nutr 9, 606-612.

17. Utter J, Schaaf D, Ni Mhurchu C et al. (2007) Food choices among students using the school food service in New Zealand. N Z Med J 120, U2389.

18. Story M, Neumark-Sztainer D \& French S (2002) Individual and environmental influences on adolescent eating behaviors. J Am Diet Assoc 102, Suppl. 3, S40-S51.

19. Morland K, Wing S \& Diez Roux A (2002) The contextual effect of the local food environment on residents' diets: the Atherosclerosis Risk in Communities Study. Am J Public Health 92, 1761-1767.

20. Neumark-Sztainer D, French S, Hannan P et al. (2005) School lunch and snacking patterns among high school students: associations with school food environment and policies. Int J Behav Nutr Phys Act 2, 14.

21. Adolescent Health Research Group (2008) Youth'07: The Health and Wellbeing of Secondary School Students in New Zealand. Technical Report. Auckland: University of Auckland.

22. Denny S, Milfont T, Utter J et al. (2008) Hand-held internet tablets for school-based data collection. BMC Res Notes 1, 52 .

23. Statistics New Zealand (2005) Statistical Standard for Ethnicity. Wellington: Statistics New Zealand.

24. Salmond C, Crampton P \& Atkinson J (2007) NZDep2006 Index of Deprivation. Wellington: University of Otago.

25. Ministry of Health (1998) Food and Nutrition Guidelines for Healthy Adolescents: A Background Paper. Wellington: Ministry of Health.

26. Ministry of Education (2007) State of Education in New Zealand 2007. Wellington: Ministry of Education.

27. Howden-Chapman P \& Tobias M (editors) (2000) Social Inequalities in Health: New Zealand 1999. Wellington: Ministry of Health.

28. Crawford PB, Obarzanek E, Schreiber GB et al. (1995) The effects of race, household income, and parental education on nutrient intakes of 9- and 10-year-old girls. NHLBI Growth and Health Study. Ann Epidemiol 5, 360-368.

29. Johnson RK, Smiciklas-Wright $\mathrm{H}$, Crouter AC et al. (1992) Maternal employment and the quality of young children's diets: empirical evidence based on the 1987-1988 Nationwide Food Consumption Survey. Pediatrics 90, 245-249. 
30. Rasmussen M, Krolner R, Klepp KI et al. (2006) Determinants of fruit and vegetable consumption among children and adolescents: a review of the literature. Part I: quantitative studies. Int J Behav Nutr Phys Act 3, 22.

31. Utter J, Scragg R, Schaaf D et al. (2006) Nutrition and physical activity behaviours among Maori, Pacific and NZ European children: identifying opportunities for population-based interventions. Aust $N Z J$ Public Health 30, $50-56$.
32. Blakely $\mathrm{T} \&$ Pearce N (2002) Socio-economic position is more than just NZDep. $N Z$ Med J 115, 109-111.

33. Larson NI, Story MT \& Nelson MC (2009) Neighborhood environments: disparities in access to healthy foods in the US. Am J Prev Med 36, 74-81.

34. Yancey AK, Cole BL, Brown R et al. (2009) A cross-sectional prevalence study of ethnically targeted and general audience outdoor obesity-related advertising. Milbank $Q$ 87, 155-184. 